\title{
Sistema de Informações Executivas: Suas Características e Reflexões sobre sua Aplicação no Processo de Gestão
}

\author{
Ilse Maria Beuren \\ Doutora em Controladoria e Contabilidade - FEA/USP - Professora Titular do Departamento de Ciências \\ Contábeis da Universidade Federal de Santa Catarina - UFSC.
}

Luciano Waltrick Martins

Mestre em Administração - CPGA/UFSC.

RESUMO

A necessidade que têm as organizações de aprimorar seu processo de gestão, face ao anseio de otimizar o desempenho e garantir o cumprimento de sua missão, faz com que seus administradores busquem alternativas na tecnologia da informação. O sistema de informações executivas é uma ferramenta que direciona o gestor a ações que buscam contribuir para esse fim.

Dentro desse contexto, o presente artigo objetivou realizar uma incursão teórica nas características de um sistema de informações executivas, além de fazer algumas reflexões sobre sua aplicação no processo de gestão empresarial.

Observa-se que, normalmente, há falta de integração entre os sistemas de informação das organizações, além de dificuldade dos gestores no acesso às informações contidas nestes sistemas. Assim, as características desejadas pelos gestores podem ser encontradas em um sistema de informações executivas, desde que seja adaptado às suas necessidades.

Palavras-chave: Tecnologia da Informação, Sistema de Informações Executivas, Processo de Gestão..
ABSTRACT

Managers are constantly urged to optimize performance and guarantee the fulfillment of their mission. Consequently, they are confronted with the need to improve the management process. This makes them look for alternatives in information technology, since an effective executive information system is a tool that helps the manager in performing actions that contribute to the attainment of this goal.

In this context, the present article aims at verifying what characteristics an executive information system has to possess in order to support the management process.

The study shows both a lack of integration among institutional information systems and the difficulties the managers are confronted with in trying to access the information provided by the systems. The necessary characteristics of an executive information system were also verified among managers.

Key words: information technology, executive information system, management process. 


\section{INTRODUÇÃO}

A última metade do século $X X$ foi um período em que houve várias invenções que marcaram a história da humanidade. Certamente, parte disso é resultante de investimentos significativos feitos, principalmente, na pesquisa. No âmbito tecnológico nota-se uma série de ferramentas inovadoras que impulsionaram muitos setores. Alguns exemplos práticos são a invenção do satélite e o advento da informática. E, mais recentemente, a vinda da Internet. São criações que mudaram as organizações nos seus aspectos estrutural, funcional, comportamental e de desempenho.

Dessa forma, as instituições começaram a valorizar um recurso primordial para sua sobrevivência: a informação. As empresas perceberam que pela gestão da informação tornam-se competitivas, organizadas e aptas a responder às mudanças exigidas pelo cenário mundial.

Numa perspectiva histórica, os sistemas de informação evoluíram de acordo com as necessidades organizacionais. Primeiramente, esses sistemas eram desenvolvidos pela própria empresa, em um local denominado Centro de Processamento de Dados (CPD), e tinham como objetivo agilizar seus procedimentos internos e departamentos administrativos; limitavam-se porém a processar apenas as operações realizadas diariamente.

Em uma segunda fase, inicia-se o desenvolvimento de automação das linhas de produção da indústria e a preocupação em gerar sistemas que possibilitem suprir as necessidades de informação de gerentes e executivos, para tomada de decisão.

Em um terceiro momento, já na década de 80, com o surgimento dos microcomputadores e das redes locais, nasceram diversas empresas ligadas exclusivamente ao desenvolvimento de sistemas de informação e de gerenciamento da tecnologia da informação. Não demorou muito, essas empresas conseguiram seu lugar no mercado e substituíram, muitas vezes, o papel antes exercido pelo CPD. As empresas resolveram terceirizar, diminuindo custos na locação de mainframes e pessoal, socializando os microcomputadores e seus sistemas pela companhia, e criando uma cultura interna de informática.

Em uma quarta instância, nos anos 90, quando as empresas estavam com seus sistemas equilibrados e funcionando adequadamente, surge a neces- sidade de levar a seus clientes e fornecedores os benefícios resultantes da informática, gerando, assim, uma relação mais íntima e de acesso facilitado. Como exemplo, as integrações on-line com fornecedores para reposição de estoque, o que possibilitou implementar a metodologia just-in-time, e atendimentos bancários eletrônicos, que permitiram a seus clientes acessar e gerenciar suas contas em diversos locais além da agência, disponíveis 24 horas por dia

Nos dias atuais, vive-se uma nova transformação Com a chegada da Internet, as organizações estão se moldando a mais esta ferramenta. Os benefícios trazidos ainda estão sendo implementados. Novas formas de negócio e prestação de serviços estão sendo inventadas. Já existem os conceitos de e-business (negócios pela Internet) e e-commerce (comércio eletrônico), que revolucionam as tradicionais maneiras de interagir com os clientes. Caíram, definitivamente, as barreiras geográficas. Novas leis estão sendo criadas para legalizar e oficializar transações de compra e venda, defender direitos autorais e regulamentar impostos. Uma nova era está surgindo.

$\mathrm{Na}$ área de desenvolvimento de sistemas de informação, aparece como opção para as organizações, um novo produto denominado ERP - Enterprise Resource Planning ou Planejamento de Recursos Empresariais, o qual foi concebido para atuar em todos os momentos do negócio, desde a concepção de um produto, compra de itens, manutenção de inventário, área orçamentária e financeira, até auxiliar na gestão de recursos humanos, interação com fornecedores e clientes e acompanhar ordens de produção. Há, também, módulos específicos voltados para gerentes e executivos, nos quais as informações são filtradas e resumidas, indicando tendências e visualizando padrões de referência para tomada de decisões de cunho estratégico.

Encontra-se entre os diversos tipos de sistemas de informações, o denominado EIS - Executive Information System, o qual foi traduzido como SIE Sistema de Informações Executivas. Este tipo de sistema de informação tem como objetivo primordial ampliar as possibilidades de alternativas para problemas organizacionais, assim como permitir a exploração das informações disponíveis que possibilitem ao gestor traçar novos rumos e comportar-se de maneira pró-ativa face ao ambiente em que se encontra. 
Neste sentido, o presente estudo objetivou fazer uma incursão teórica nas características de um sistema de informações executivas, além de fazer uma reflexão sobre sua aplicação no suporte ao processo de gestão empresarial.

A literatura existente sobre sistemas de informações é ampla, mas a maioria das obras é dedicada aos sistemas de informações nas áreas transacionais e gerenciais. Os sistemas de informações que atuam no segmento transacional visam a concretizar e armazenar as operações realizadas na organização. Nas instituições financeiras, por exemplo, uma transação pode representar um depósito, saque ou aplicação feita pelo correntista. Em um hospital, uma transação pode ser considerada como a internação de um paciente, ou uma requisição de exame médico.

Estas transações são manipuladas e gerenciadas pelos sistemas de informações gerenciais - SIG. Estes sistemas têm como objetivo auxiliar a organização a alcançar maior eficiência. Propiciam, aos gerentes, informações que orientam as tomadas de decisão e o monitoramento de suas tarefas.

No entendimento de Dalfovo e Rodrigues (1998, p.43), a sustentação teórica de sistemas de informações para os altos escalões das organizações é praticamente nula. Reflete-se, com isso, o pouco ou nenhum contato do executivo com a informática, o que não lhe permite utilizar a informação de maneira estratégica.

Colocar a organização em patamares de competitividade é o objetivo de todo executivo. Sem a utilização de um sistema de informações, como recurso estratégico para esta finalidade, torna-se mais difícil garantir a capacidade competitiva do empreendimento. Desse modo, a criação de um contexto tecnológico voltado ao executivo, que forneça suporte na tomada de decisão, tornou-se imperativo em época de expansão de uma economia globalizada e com mercados altamente concorridos.

Em um ambiente de negócios que requerem flexibilidade, o processo de tomada de decisão necessita rapidez no processamento de dados pela tecnologia, bem como disponibilidade e acesso a informações. Isto facilita a leitura do contexto. Desta forma, as alternativas para definir uma estratégia de ação serão melhor fundamentadas e terão maiores probabilidades de êxito.

\section{DADO, INFORMAÇÃO E CONHECIMENTO}

A distinção entre dado, informação e conhecimento torna-se imprescindível para uma compreensão melhor de sistema de informação. Oliveira (1992, p.34) afirma que "dado é qualquer elemento identificado em sua forma bruta que por si só não conduz a uma compreensão de determinado fato ou situação." A partir do dado transformado, o executivo pode ter consigo um elemento de ação. Desse modo, a "informação é o dado trabalhado que permite ao executivo tomar decisões".

Nesse sentido, Almeida (1999, p.307) menciona a existência de uma relação íntima entre informação e decisão, visto que decisões são tomadas no presente sobre eventos que se concretizarão no futuro. Afirma que "o conceito de informação está vinculado a uma mudança de estado a respeito do evento. Assim, a informação configura-se como um conhecimento disponível, para uso imediato, que permite orientar a ação." Para criar uma informação pela relação estabelecida entre dados, exige-se conhecimento. Stair (1998, p.05) menciona que para definir uma relação se requer conhecimento.

De acordo com Alter (1992, p.81), conhecimento "é a combinação de instintos, idéias, regras e procedimentos que guiam ações e decisões." Explica, ainda, que dados são formatados, filtrados e manipulados para criar informação. A conversão de dados em informação é baseada em conhecimento acumulado sobre como formatar, filtrar e manipular dados para serem úteis em uma situação.

Assim, para haver um gerenciamento eficiente e eficaz das informações na organização, faz-se necessário estabelecer procedimentos de maneira estruturada, que forneça aos gestores condições de desempenho, conforme o processo de gestão definido pela instituição. O mecanismo encontrado para fornecer este suporte gerencial é o sistema de informação.

\section{SISTEMA DE INFORMAÇÃO}

Um sistema de informação consiste em uma soma estruturada de elementos. Mosimann, Alves e Fisch (1993, p.52) conceituam sistema de informação como "uma rede de informações cujos fluxos alimentam o processo de tomada de decisões, não apenas da 
empresa como um todo, mas, também, de cada área de responsabilidade."

Campos Filho (1994, p.34) explicita que o sistema de informação baseia-se em quatro componentes reunidos de modo a permitir o melhor atendimento aos objetivos da organização:

a) a informação (dados formatados, imagens, sons e textos livres);

b) os recursos humanos (que coletam, armazenam, recuperam, processam, disseminam e utilizam as informações);

c) as tecnologias de informações (o hardware e o software); e

d) as práticas de trabalho (métodos utilizados).

As práticas de trabalho, segundo Alter (1992, p.07), são as formas, maneiras e métodos utilizados pelas pessoas da organização para realizar os seus serviços. Elas estão intimamente ligadas às ferramentas tecnológicas e às informações para comunicação, realização de tomada de decisão e outras tarefas necessárias ao negócio.

As tecnologias de informações, de acordo com Alter (1992, p.09), compreendem o hardware e software destinados a tarefa de processamento de dados e que capturam, manipulam, armazenam, recuperam e transmitem as informações. Salienta que a tecnologia da informação é um componente do sistema de informação e não pode ser confundido como se este elemento fosse o todo. A tecnologia de informação é o ferramental do qual se utiliza a prática de trabalho.

Por sua vez, os recursos humanos, conforme Campos Filho (1994, p.35), estão incluídos no sistema de informação para, a não ser em casos totalmente automatizados, coletar, processar ou usar dados. A vinculação entre os recursos humanos e as práticas de trabalho demonstra que elas afetam os recursos humanos, ao passo que as características dos recursos humanos no sistema determinam quais práticas serão viáveis e adequadas.

\section{SISTEMA DE PROCESSAMENTO DE TRANSAÇÕES (SPT)}

O sistema de processamento de transações, também denominado sistema eletrônico de processamento de dados, é definido por Mcleod (1993, p.390) como a "manipulação ou transforma- ção de símbolos tais como números e letras para o propósito de aumentar sua utilidade."

De acordo com Alter (1992, p.127), "um sistema de processamento de transações coleta e armazena dados sobre transações e algumas vezes controla decisões que são feitas como parte de uma transação." Uma transação é qualquer troca relacionada com negócios, como pagamento a empregados, vendas a clientes e pagamento a fornecedores.

Na perspectiva administrativa, um SPT é destinado a desempenhar um papel de suporte às atividades da organização empresarial. De acordo com Stair (1998, p. 183), o SPT é usado para dar "suporte às atividades do pessoal não-gerencial e pelos níveis da administração operacional da organização."

Um SPT bem desenvolvido e implantado tornase uma fonte de dados valiosa, como entrada aos outros sistemas de informação. O SPT é o alicerce que sustenta a integridade e precisão da informação gerada, assegurando a confiabilidade dos sistemas de informação hierarquicamente acima dele.

\section{SISTEMA DE INFORMAÇÕES GERENCIAIS (SIG)}

Um sistema de informações gerenciais é descrito por Mcleod (1993, p.427) como "um sistema baseado em computador que faz avaliações das informações para usuários com necessidades similares." Afirma, ainda, o autor que as informações são utilizadas por administradores e não administradores para tomadas de decisão e para resolver problemas.

Para Stair (1998, p.38), "um sistema de informações gerenciais (SIG) é um agrupamento organizado de pessoas, procedimentos, banco de dados e dispositivos usados para oferecer informações de rotina aos administradores e tomadores de decisões."

Segundo Furlan, Ivo e Amaral (1994, p.28), "nos sistemas MIS, o foco passa para as atividades de planejamento e integração dos sistemas." Identificam como principais características do SIG: a) foco na informação direcionada a gerentes de nível médio; b) fluxo de informações estruturado; c) integração dos sistemas por área funcional; e d) geração de relatórios e consultas, normalmente com uso de um banco de dados. 
A unificação e integração de sistemas, no entendimento de Stair (1998, p.213), são realizadas freqüentemente com a adoção de um banco de dados compartilhado. Este banco de dados comum serve não só para interligar o SIG, como também pode integrar os SPT's da organização com os vários SIG's funcionais.

Como o foco é a saída das informações para o gerente, a geração dos relatórios em vez de mostrar as transações ocorridas, passa a apontar, por meio de resumos e filtragens, indicadores-chaves para o monitoramento e análise das informações. Dessa forma, entende-se que o sistema de informações gerenciais proporciona ao gestor condições de controlar as diversas rotinas administrativas e é fonte orientadora para o processo decisório.

\section{SISTEMA DE INFORMAÇÕES EXECUTIVAS (SIE)}

Foi mantido o termo SIE na sua forma original, mesmo que alguns autores o denominem como Enterprise Information System, em virtude de novas abordagens, que modificam substancialmente as bases que fundamentam o termo original.

\section{Conceituação de SIE}

$\mathrm{Na}$ literatura encontram-se diversas definições de $\mathrm{SIE}$, as quais convergem para um tipo de sistema de informações que fornece suporte ao processo decisório para o alto escalão da organização. Segundo Pozzebon e Freitas (1996, p.29), o SIE "é uma solução em termos de informática que disponibiliza informações corporativas e estratégicas para os decisores de uma organização, de forma a otimizar sua habilidade para tomar decisões de negócios importantes."

Mcleod (1993, p. 586) ressalta que "um sistema de informações executivas é um sistema que provê informações para o executivo do desempenho global da firma." Considera que o fornecimento destas informações ao executivo pode ser facilmente recuperado e pode ter vários níveis de detalhe. Assim, podese partir de um nível superficial de análise e prosseguir até um nível de detalhamento mais profundo e desejado.

Um sistema de informações executivas, conforme Alter (1992, p.136), é "um sistema altamente interativo provendo os dirigentes e executivos com acesso flexível à informação para monitorar resultados das operações e condições gerais do negócio." Sua preocupação gravita em torno da importância do SIE no acompanhamento dos resultados das operações realizadas pela organização. O SIE é desenhado para ajudar os executivos a encontrar as informações que necessitam.

Observa-se nas considerações expostas uma relação direta com a praticidade na utilização do SIE pelo alto executivo. Os executivos que tomam decisões estratégicas não dispõem do tempo necessário para realizar um treinamento em sistemas desenvolvidos tradicionalmente para usuários de escalões mais baixos. Portanto, o sistema deve ser criado de maneira que sua operação seja intuitiva e dê legibilidade e compreensão dos resultados de forma instantânea.

\section{A Evolução Histórica do SIE}

Segundo Furlan, Ivo e Amaral (1994, p.06), o termo sistema de informações executivas (SIE) foi criado no final da década de 1970, a partir de trabalhos desenvolvidos no Massachusetts Institute of Tecnology (MIT) por pesquisadores como Rockart e Treacy.

O surgimento do SIE é uma resposta para preocupações decorrentes da pouca utilização da informática por executivos e pouco interesse em se habituarem com ela. Dalfovo e Rodrigues (1998, p.43) afirmam que "o suporte efetivo aos executivos não tem tido um avanço significativo. Como usuários, os executivos somente têm utilizado a informática de forma indireta e tangencial." Adiciona-se a isto a dificuldade de transpor a barreira tecnológica e a nãocondição natural de operar e lidar computadores, impossibilitando a utilização das informações como recurso estratégico.

Desde o início dos estudos e implementação de SIE, no fim da década de 1970, algumas modificações foram realizadas para ajustá-los às novas necessidades de administração, bem como às novas tecnologias. Assim, segundo Turban e Walls apud Pozzebon (1998, p.22), tem-se como objetivo maior, na primeira fase do SIE, proporcionar aos dirigentes das organizações a identificação dos problemas e oportunidades o mais cedo possível. As funções utilizadas continuam a fazer parte dos sistemas desenvolvidos atualmente: relatórios de exceção e de evo- 
lução de indicadores-chave, técnicas de drill down $n^{1} \mathrm{e}$ integração com correio eletrônico.

A segunda fase surgiu no fim da década de 1980, de acordo com Rockart e Delong apud Pozzebon (1998, p.22), com a introdução do ESS - Executive Support System, no qual foram incorporadas funções de comunicação, automação de escritório e análise às tradicionais funções de monitoramento e controle.

A terceira fase emergiu na década de 1990, conforme Turban e Walls apud Pozzebon (1998, p.23), com a difusão dos microcomputadores e as redes locais. Há que se ressaltar a preocupação em acessar as informações internas e externas da organização rapidamente, em qualquer lugar.

A questão que paira atualmente são as discussões sobre o direcionamento do SIE: executive or everybody (executivo ou para todos)? A quem realmente se destina o SIE? O tema debatido por diversos autores compreende a reflexão sobre o alto custo de desenvolvimento do sistema para poucos usuários e sobre como avaliar seu desempenho na organização. Existe a dificuldade, contudo, de utilizá-lo em larga escala na empresa, tendo em vista os mais diversos grupos de usuários que necessitam de especificidades diferentes e que precisam estar embutidas em um mesmo sistema de informações.

A tendência da próxima fase do SIE, direcionandoo para todos dentro da organização, faz com que o limite que existe entre o SIE e o SAD (Sistema de Apoio à Decisão) seja cada vez mais estreito. A Figura 1 mostra a hierarquia entre os diferentes tipos de sistemas de informações abordados neste estudo.

\section{Figura 1 - Pirâmide dos Sistemas de Informação}

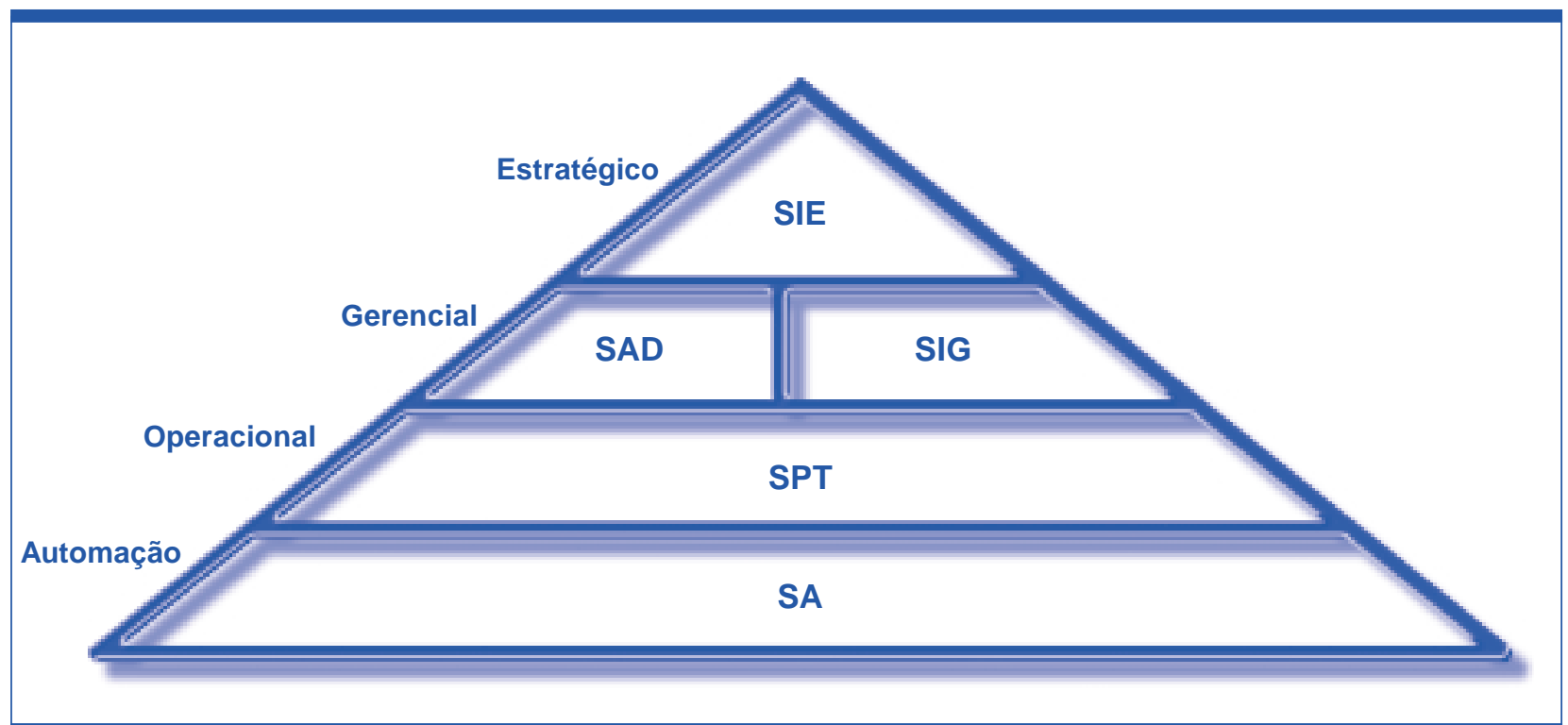

Fonte: FURLAN, José Davi, IVO, Ivonildo da Motta e AMARAL, Francisco Piedade. Sistema de Informação Executiva=EIS-Executive Information System: como integrar os executivos ao sistema informacional das empresas, fornecendo informações úteis e objetivas para suas necessidades estratégicas e operacionais. São Paulo: Makron Books, 1994b. p.26.

$\mathrm{Na}$ base da pirâmide estão concentrados os sistemas de automação (SA). Este tipo de sistema não foi abordado neste trabalho e refere-se aos sistemas de automação industrial, comercial, bancária e de escritório.

No segundo nível estão os sistemas de processamento de transações (SPT). Este gênero de sistema de informação refere-se aos sistemas computacionais como o de faturamento, folha de pagamento, contas a receber e a pagar, contábil e tesouraria.

O terceiro estágio compreende os sistemas gerenciais e divide-se em dois módulos: o SAD e o SIG. O sistema de apoio à decisão (SAD), o qual não foi abordado neste estudo, é conceituado por Stair (1998, p.38) como "um grupo organizado de pessoas, procedimentos, banco de dados, e dispositivos usa-

\footnotetext{
${ }^{1}$ É um recurso do sistema SIE que significa um aprofundamento das informações que conduzem o executivo até o grau de detalhe necessário (Furlan, Ivo e Amaral, 1994, p.27)
} 
dos para dar apoio à tomada de decisões referentes a problemas específicos". Para Sprague (1991, p. 10), o SAD caracteriza-se como "um sistema computacional interativo que ajuda os responsáveis pela tomada de decisões a utilizar dados e modelos para resolver problemas não estruturados." STAIR (1998, p.232) corrobora esta idéia e acrescenta que o foco de um SAD "está na eficácia da tomada de decisões em face de problemas comerciais não estruturados ou semiestruturados."
Por sua vez, o sistema de informações gerenciais (SIG), conforme Furlan, Ivo e Amaral (1994, p.28), tem como público-alvo os níveis gerenciais da empresa, e oferece informações sumarizadas, contemplando o comportamento dos negócios nos períodos passados através de totalizações e consolidando as operações realizadas.

Turban e Schaeffer (1991, p. 353) comparam os tipos de sistemas SIE, SAD e SIG, conforme demonstrado no Quadro 1.

\section{Quadro 1 - Comparativo entre modelos SIE, SAD e SIG}

\begin{tabular}{|c|c|c|c|}
\hline DIMENSÃO & SIE & SAD & SIG \\
\hline Foco & $\begin{array}{l}\text { Acesso aos status indicadores de } \\
\text { desempenho }\end{array}$ & Análise e apoio à decisão & $\begin{array}{l}\text { Processamento de } \\
\text { informações }\end{array}$ \\
\hline Usuário típico & Executivos & Gerentes intermediários e analistas & Gerentes de nível médio \\
\hline Objetivo & Conveniência & Eficácia & Eficiência \\
\hline Aplicação & $\begin{array}{l}\text { Avaliação de desempenho, } \\
\text { acompanhamento de fatores } \\
\text { críticos de sucesso }\end{array}$ & Tomada de decisão operacional & $\begin{array}{l}\text { Controle de produção, } \\
\text { projeção de vendas, análise } \\
\text { de custos, etc. }\end{array}$ \\
\hline $\begin{array}{l}\text { Apoio oferecido à } \\
\text { decisão }\end{array}$ & $\begin{array}{l}\text { Indireto, problemas de alto nível e } \\
\text { não estruturados }\end{array}$ & Apoio direto & Direto ou indireto \\
\hline Banco de dados & Especial & Especial & Da empresa \\
\hline Tipo de informação & $\begin{array}{l}\text { Operações internas, tópicos } \\
\text { críticos, informações externas, } \\
\text { exceções }\end{array}$ & $\begin{array}{l}\text { Informação de apoio para } \\
\text { situações específicas }\end{array}$ & $\begin{array}{l}\text { Relatório das } \\
\text { operações internas, } \\
\text { fluxo estruturado }\end{array}$ \\
\hline Uso principal & Acompanhamento e controle & $\begin{array}{l}\text { Planejamento, organização e } \\
\text { controle }\end{array}$ & Controle \\
\hline $\begin{array}{l}\text { Adaptação ao } \\
\text { usuário }\end{array}$ & $\begin{array}{l}\text { Adaptável ao estilo decisório } \\
\text { do executivo }\end{array}$ & $\begin{array}{l}\text { Permite recursos de simulação, } \\
\text { julgamento e escolha de estilos de } \\
\text { diálogos }\end{array}$ & Normalmente nenhuma \\
\hline Recursos gráficos & Essencial & Parte integrada de muitos SAD & Desejável \\
\hline $\begin{array}{l}\text { Facilidade } \\
\text { conversacional }\end{array}$ & Essencial & Essencial & Desejável \\
\hline $\begin{array}{l}\text { Tratamento das } \\
\text { informações }\end{array}$ & $\begin{array}{l}\text { Filtra e resume informações, } \\
\text { apresentando exceções e tópicos } \\
\text { essenciais }\end{array}$ & $\begin{array}{l}\text { Utiliza informações geradas pelo } \\
\text { SIG ou SIE como input (entrada) }\end{array}$ & $\begin{array}{l}\text { Sumariza e relata informações } \\
\text { para serem tratadas pelos } \\
\text { usuários }\end{array}$ \\
\hline $\begin{array}{l}\text { Detalhamento de } \\
\text { informações }\end{array}$ & $\begin{array}{l}\text { Acesso instantâneo aos detalhes } \\
\text { de qualquer resumo }\end{array}$ & Podem ser programados & Inflexibilidade dos relatórios \\
\hline Banco de modelos & Pode ser acrescentado & Essência do sistema & Disponível, mas não gerenciável \\
\hline Desenvolvimento & Especialista em sistemas & $\begin{array}{l}\text { Usuários, com treinamento } \\
\text { oferecido pelos especialistas }\end{array}$ & Especialistas em sistemas \\
\hline
\end{tabular}

Fonte:TURBAN, Efraim e SCHAEFFER, Donna M. Uma comparação entre sistemas de informação para executivos, DSS e sistemas de informação gerencial. In: SPRAGUE JR, Ralph H. e WATSON, Hugh J. (Org.). Sistemas de apoio à decisão: colocando a teoria em prática. Rio de Janeiro: Campus, 1991 p. 345-362, p.353. 
Nota-se que o foco direcionado ao SIE está relacionado aos status indicadores de desempenho. Isto demonstra a vinculação direta com a natureza estratégica em que o SIE foi concebido. Segundo Fischmann e Zilber (1999, p.173), "uma possível conceituação de desempenho no âmbito das organizações é a capacidade da empresa atingir seus objetivos estratégicos através da implementação de estratégias adotadas dentro do seu processo de planejamento. A empresa, dessa forma, deve contar com um sistema de indicadores de desempenho que permita a verificação do efetivo sucesso de sua gestão estratégica."

A criação do SIE, conforme Turban e Schaeffer (1991, p.353), é uma classe de sistemas de informação que apoia o executivo na obtenção de insights ${ }^{2}$ e persegue os fatores críticos de sucesso, auxiliando, assim, ao decisor, na identificação de problemas e oportunidades da organização. Martin apud Lima (1998, p.39) afirma que os SIE "são especialmente projetados para ajudar o executivo a obter insights e rastrear os fatores críticos de sucesso. O objetivo de um sistema de informação executiva é ajudar o decisor na assimilação rápida de informações e na identificação de problemas e oportunidades, não é uma ajuda na análise de problemas ou na sua resolução."

O SIE foi concebido, portanto, para servir como uma eterna mira, tendo como alvo a missão, objetivos e metas da organização, utilizando-se dos indicadores de desempenho para sua avaliação e realinhamento. Neste sentido, Matthews e Shoebridge apud Lima (1998, p.39) afirmam que "a ênfase dos sistemas de informação executiva recai no entendimento de questões, tais como o que se quer atingir com o negócio, como se espera atingir tais objetivos e como medir seu progresso."

Por outro lado, Pozzebon (1998, p.23) considera que a tendência do estreitamento dos limites que separam o SIE do SAD, é uma conseqüência, tendo em vista o alargamento do escopo do SIE como ferramenta de auxílio à tomada de decisão. Isto faz com que as fronteiras não sejam claramente definidas. Para Stair (1998, p.232-245), o SIE e o SAD integram o que denomina de sistemas de suporte à decisão (SSD). Neste sentido, entende que o SIE pode ser utilizado além dos altos executivos e do presidente da companhia, também por funcionários dos níveis mais baixos da estrutura organizacional, compartilhando informações provenientes dos mesmos bancos de dados e redes de comunicação.

Mcleod (1993, p.596) ressalta que mais esforços têm sido feitos em aceitar o SIE em outras aplicações. É possível verificar novas classes de SIG e SAD desenvolvidos para administradores de níveis hierárquicos mais baixos, os quais contêm muitas características do SIE. Afirma, ainda, que "os SIG e SAD de amanhã parecerão como os SIE de hoje."

A ocorrência dessa integração faz surgir a necessidade de uma adequação daquela pirâmide que ilustra a hierarquia dos sistemas de informação, conforme mostra a Figura 2.

\section{Figura 2 - O Surgimento dos conceitos de OLAP e OLTP}

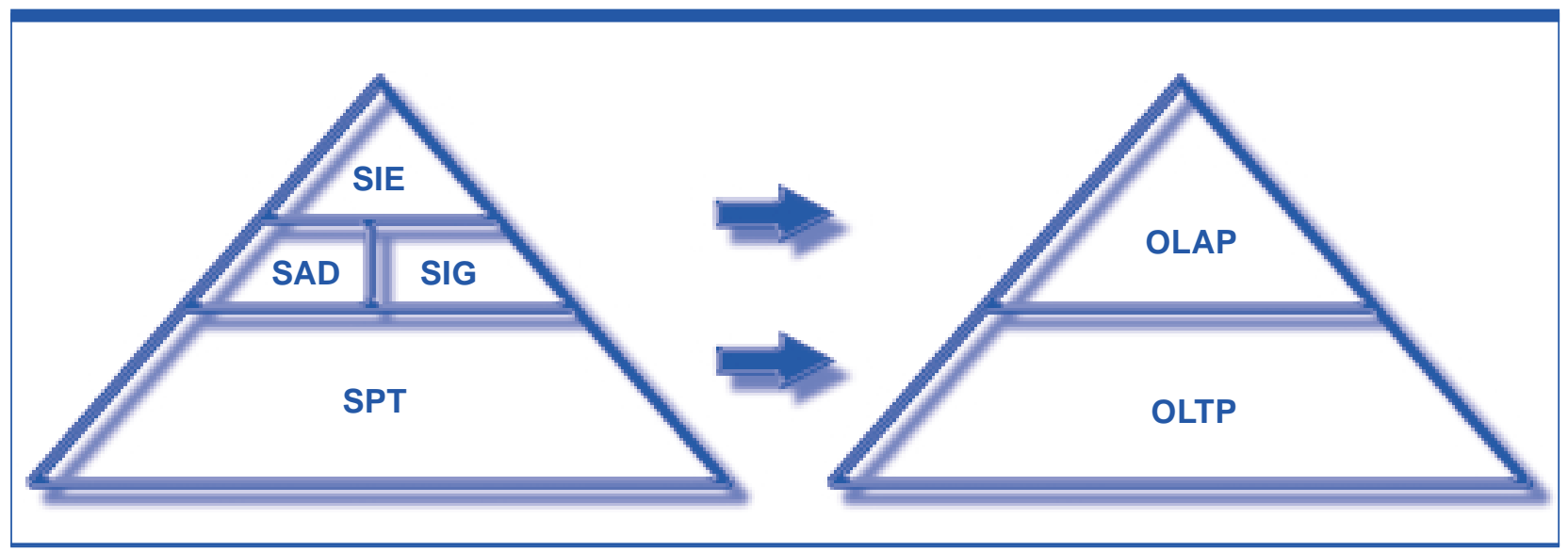

Fonte: Adaptado de POZZEBON, Marlei. Um modelo de E.I.S. - Enterprise Information System - que identifica características para comportamentos proativos na recuperação de informações. 1998. Dissertação - Universidade Federal do Rio Grande do Sul, Porto Alegre. p. 25.

\footnotetext{
${ }^{2}$ Insights é um termo utilizado para designar a compreensão de uma coisa, fato ou contexto.
} 
De acordo com Pozzebon (1998, p.25), a camada em que se encontra o SPT corresponde ao OLTP On-line Transaction Processing ou Processamento Transacional On-line. E as camadas superiores em que se encontram o SIG, SAD e SIE, correspondem ao OLAP - On-line Analytical Processing ou Processamento Analítico On-line, que demonstram a tendência ao desenvolvimento de sistemas híbridos, abrangentes e com múltiplas funções.

Por fim, declara que há uma forte perspectiva futura quanto a uma nova denominação e congraçamento entre os sistemas que formam o OLAP, e sugere uma alteração no significado da sigla SIE de Sistema de Informação Executiva para Sistema de Informação Empresarial, no qual o "Executive" cede seu lugar para "Enterprise".

\section{Elementos Característicos esperados em um SIE}

$\mathrm{Na}$ evolução ocorrida, através do tempo, com o SIE, é possível mapear uma série de características que vêm marcar este modelo de sistema de informação. Essas peculiaridades encontradas são entendidas como essenciais, e outras são incorporadas graças ao avanço tecnológico e às mudanças que advêm da administração dos negócios, aos quais os SIE's precisam se adaptar.

Algumas dessas características, consideradas como fundamentais, são relatadas em duas pesquisas de campo realizadas por Wagner Bronze Damiani, uma nos Estados Unidos, com apoio da University of Texas at Austin, e a outra no Brasil, com apoio da Escola de Administração de Empresas de São Paulo, da Fundação Getúlio Vargas. A população que compõe a amostra dos respondentes foi selecionada usando o critério de classificação das 500 maiores empresas, de acordo com a revista "Fortune" de 15 de maio de 1995, no primeiro caso, e das 500 Melhores e Maiores da revista "Exame", de agosto de 1995, no segundo caso.

De acordo com Damiani (1998, p. 40), foi efetuada uma identificação das características presentes nos SIE's em uso pelas empresas: ambiente Windows, videoconferência, touch-screen ${ }^{3}$, atualização em tempo real, tempo para implementar melhorias, uso de hipertexto, consolidação, agenda integrada, drill down de informações, correio eletrônico, informações externas e simulações.
Furlan, Ivo e Amaral (1994, p.09) também mencionam algumas características encontradas nos sistemas de informações executivas:

a) os SIE destinam-se a atender às necessidades de informação dos executivos;

b) possuem apresentação de dados através de recursos gráficos de alta qualidade;

c) recuperam informações de forma rápida para a tomada de decisão;

d) oferecem facilidade de uso, intuitivo, sem necessidade de treinamento específico em informática;

e) são desenvolvidos de modo a se enquadrarem na cultura da empresa e no estilo de tomada de decisão de cada executivo;

f) filtram, resumem, acompanham e controlam dados ligados aos indicadores de desempenho dos fatores críticos de sucesso;

g) utilizam informações do ambiente externo (concorrentes, clientes, fornecedores, indústrias, governo, tendências de mercado); e

h) proporcionam acesso a informações detalhadas subjacentes às telas de sumarização organizadas numa estrutura top-down.

Para Stair (1998, p. 246), os SIE's devem ser "extremamente fáceis de usar, dar suporte a todos os níveis de tomadas de decisões estratégicas, ser facilmente personalizados e ter abordagem e apresentação flexíveis." Cita como principais pontos: facilidade de uso, oferece uma vasta gama de recursos computacionais, manipula uma variedade de dados internos e externos, quantitativos e qualitativos, executa sofisticadas análises de dados, oferece alto grau de especialização, propicia flexibilidade; oferece recursos abrangentes de comunicações e proporciona suporte a todos os aspectos da tomada de decisões.

Por sua vez, Pozzebon e Freitas (1996, p.21) sintetizam os atributos que se esperam de um SIE, como segue:

a) uma interface totalmente amigável;

b) deve ser claro e objetivo, explorando intensivamente recursos gráficos - cores, símbolos, ícones, imagens e gráficos;

c) Drill down - a partir de visualizações globais e de dados resumidos é possível um aprofundamento até o nível de detalhamento desejado; e

\footnotetext{
${ }^{3}$ É um recurso tecnológico empregado no monitor em que o usuário seleciona opções de um menu através das mãos.
} 
d) deve fornecer informações críticas e indicadores de desempenho.

As características desejadas em um SIE, de acordo com Turban (1993, p.401), podem ser divididas nas categorias: qualidade da informação, interface com o usuário e capacidade técnica. O Quadro 2 apresenta as características cabíveis em cada uma dessas categorias.

\section{Quadro 2 - Características de um SIE}

\begin{tabular}{|c|c|c|}
\hline Qualidade da informação & Interface com o usuário & Capacidade técnica \\
\hline Ser flexível & $\begin{array}{l}\text { Contém interface gráfica sofisticada para o } \\
\text { usuário }\end{array}$ & Acesso a informações agregadas, globais \\
\hline Produz informação correta & Contém uma interface amigável & Extensivo uso de dados externos \\
\hline $\begin{array}{l}\text { Produz informação } \\
\text { oportunamente (no momento } \\
\text { em que se necessita) }\end{array}$ & $\begin{array}{l}\text { Permite acesso seguro e confidencial às } \\
\text { informações }\end{array}$ & Interpretação escrita (informal) \\
\hline Produz informação relevante & Tem um pequeno tempo de resposta & Salienta indicadores de problemas \\
\hline Produz informação completa & É acessível de muitos lugares & Hipertexto e Hipermídia \\
\hline \multirow[t]{10}{*}{ Produz informação validada } & Contém um procedimento de acesso seguro & Análise ad hoc \\
\hline & $\begin{array}{l}\text { Minimiza o uso do teclado; alternativamente } \\
\text { usa controles infra-vermelhos, mouse, touch } \\
\text { pad e touch-screen }\end{array}$ & Informações apresentadas em forma hierárquica \\
\hline & $\begin{array}{l}\text { Provê uma recuperação rápida da } \\
\text { informação desejada }\end{array}$ & Incorpora gráfico e texto na mesma tela \\
\hline & $\begin{array}{l}\text { É adaptado individualmente ao estilo } \\
\text { administrativo do executivo }\end{array}$ & Permite administrar por relatórios de exceção \\
\hline & Contém menu de ajuda & Mostra tendências, taxas e desvios \\
\hline & & Provê acesso a dados históricos e aos mais recentes \\
\hline & & $\begin{array}{l}\text { Organizado considerando os fatores críticos de } \\
\text { sucesso }\end{array}$ \\
\hline & & Capacidade de previsão, planejamento e projeção \\
\hline & & $\begin{array}{l}\text { Produz informação em vários níveis de detalhe ("drill } \\
\text { down") }\end{array}$ \\
\hline & & Filtra, condensa e percorre dados críticos \\
\hline
\end{tabular}

Fonte: Adaptado de TURBAN, Efraim. Decison Support and expert systems: management support systems. United States of America: Macmillan Publishing Company, 1993. p.401.

A qualidade da informação é a categoria na qual se destaca a preocupação com a confiabilidade da informação prestada, assim como a filtragem de informações relevantes ao gestor. Ackoff (1981, p.78) adverte que um dos problemas encontrados em um sistema de informação é o excesso de informações irrelevantes geradas, ocasionando uma quantidade de informações incapaz de ser absorvida pelo administrador. Para solucionar este problema, sugere a existência de duas funções no sistema de informação, que são a triagem e a condensação da informação.
Em relação à interface com o usuário, o uso de tecnologias por parte dos administradores, normalmente, não os deixa à vontade para um efetivo manuseio. No entendimento de Furlan, Ivo e Amaral (1994, p.81), "os executivos esperam que a informática traga de fato o que precisam de modo operacionalmente simples e intuitivo, sem a necessidade de treinamento especial."

Neste sentido, Mosimann, Alves e Fisch (1993, p.63) salientam que muitos gestores têm medo de demonstrar uma possível ignorância ao avaliar um sistema automatizado. Acreditam que somente farão 
uso eficaz do sistema quando "o compreenderem o suficiente para a avaliação de seu desempenho, e, consequentemente, para seu controle."

A capacidade técnica de um SIE utiliza-se da tecnologia para implementar as condições necessárias às duas categorias mencionadas: a qualidade da informação e a interface com o usuário. Esta ca- tegoria também incorpora o domínio da flexibilidade e manuseio das informações, que são proporcionados na elaboração do sistema.

O Quadro 3 procura compilar as características do SIE, comuns entre os autores citados, utilizando o critério do maior número de vezes em que a característica foi apresentada.

\section{Quadro 3 - Compilação dos elementos característicos em um SIE}

\begin{tabular}{|c|c|}
\hline Característica & Descrição \\
\hline Drill Down & Possibilitar o aprofundamento no nível de detalhe das informações \\
\hline Acesso a informações externas & Permitir o tratamento de informações do meio externo \\
\hline Recursos gráficos & Explorar ícones, gráficos, cores, símbolos e imagens \\
\hline Recuperação rápida da informação & Utilizar recursos tecnológicos para otimizar o tempo de resposta \\
\hline Facilidade de uso & $\begin{array}{l}\text { Utilizar o sistema com mínimo de treinamento e permitir ao usuário os recursos como: } \\
\text { touch-screen, mouse e touch pad }\end{array}$ \\
\hline Flexibilidade & Adaptável ao estilo de cada executivo \\
\hline Voltado aos fatores críticos de sucesso & $\begin{array}{l}\text { Monitorar os indicadores de desempenho da organização, auxiliando na administração dos } \\
\text { fatores críticos de sucesso }\end{array}$ \\
\hline Hipertexto & Facilitar a navegação no sistema \\
\hline Filtragem e resumo & Permitir a geração de informações selecionadas e/ou aglutinadas de interesse do executivo \\
\hline
\end{tabular}

\section{O SIE como parte integrante do Planejamento Estratégico da Empresa}

Para a implantação de um SIE é necessário que o seu planejamento esteja alinhado com o planejamento estratégico da organização. Segundo Albertin (1996, p.62), "a implementação de um sistema de informação deve estar de acordo com a estratégia de uso da tecnologia de informação da organização, que, por sua vez, deve ser coerente com a sua estratégia de negócios." Por sua vez, Alter (1992, p.589) afirma que "o planejamento do sistema de informações deve ser uma parte integrante do planejamento do negócio."

Guerreiro apud Almeida (1999, p.310) menciona que um dos princípios que devem nortear o desenvolvimento de sistemas de informação consiste no condicionamento sistêmico, no qual o sistema de informação depende do sistema de gestão e este do sistema institucional que contém as crenças e valores da instituição. De forma análoga, Beuren (1998, p.39) registra que a concepção do sistema de informações depende do sistema de gestão ao qual vai servir de suporte. Ressalta que esforços devem ser despendidos na identificação das informações necessárias ao processo de gestão e na determinação dos subsistemas que devem ser gerados.

Assim, os sistemas de informações que serão implantados, incluindo o SIE, devem fazer parte do planejamento estratégico. Furlan (1991, p.06) define o Planejamento Estratégico de Sistema de Informações como "parte integrante do Planejamento Estratégico Empresarial (formal ou informal), com enfoque gerencial para desenvolver planos de sistemas e banco de dados, definir projetos e estabelecer prioridades de forma contínua." As fases e subfases da metodologia de Planejamento Estratégico de Sistemas de Informação são apresentadas no Quadro 4. 


\section{Quadro 4 - Fases e subfases da metodologia de planejamento estratégico de sistemas de informação}

\begin{tabular}{|c|l|}
\hline Fase/Subfases & \multicolumn{1}{c|}{ Processos/Atividades } \\
\hline Primeira Fase - & Início do Planejamento Estratégico de Sistemas de Informação \\
\hline Subfase 1 - & Organização do planejamento \\
\hline Subfase 2 - & Treinamento dos participantes do planejamento \\
\hline Segunda Fase - & Análise da situação atual \\
\hline Subfase 1 - & Revisão das estratégias e operaçães do negócio \\
\hline Subfase 2 - & Avaliação dos sistemas existentes \\
\hline Terceira Fase - & Elaboração de soluções \\
\hline Subfase 1 - & Definição da arquitetura de dados \\
\hline Subfase 2 - & Definição da arquitetura de sistemas \\
\hline Subfase 3 - & Definição de estratégias gerenciais \\
\hline Subfase 4 - & Definição da arquitetura tecnológica \\
\hline Quarta Fase - & Desenvolvimento de planos \\
\hline Subfase 1 - & Desenvolvimentos de projetos de sistemas de informação \\
\hline Subfase 2 - & Definição das necessidades de recursos \\
\hline Subfase 3 - & Finalização do plano \\
\hline
\end{tabular}

Fonte: Adaptado de FURLAN, José Davi. Como elaborar e implementar o planejamento estratégico de sistemas de informação. São Paulo: Makron, McGraw-Hill, 1991. p.11.

A primeira fase se refere às atividades correspondentes à organização geral do projeto de planejamento e o treinamento dos participantes na metodologia, técnicas e ferramentas de apoio. O objetivo é estabelecer uma visão comum e as expectativas sobre o projeto, assim como as regras e responsabilidades organizacionais, o plano de trabalho e os resultados almejados com o planejamento.

Os propósitos da segunda fase são o estabelecimento de uma abordagem metodológica para efetuar o levantamento e compreensão do negócio e das necessidades de informações para o processo decisório. O caminho metodológico leva em consideração a missão, os objetivos da organização e de cada área funcional, desafios e metas em termos estratégicos, tático e operacional. Também contempla os fatores críticos de sucesso, problemas e necessidades de informação.

A subfase avaliação dos sistemas existentes tem como objetivo elaborar um inventário destes sistemas e fazer um levantamento do ambiente técnico. Com base nesta avaliação são elaboradas recomendações de melhoria de curto prazo.

$\mathrm{Na}$ etapa de elaboração de soluções é contemplada a análise de viabilidade do desenvolvimento de cenários propostos. São definidos, por meio das subfases, os modelos de dados, os aplicativos a se- rem desenvolvidos, o tipo de processamento, se distribuído ou centralizado, as alternativas estratégicas gerenciais para os sistemas de informação, assim como seus impactos e os recursos tecnológicos a serem aplicados.

A última etapa do Planejamento Estratégico de Sistema de Informação destina-se ao desenvolvimento de planos para implantar os projetos estabelecidos na fase anterior. Dentre os objetivos prescritos em cada subfase, destaca-se a priorização de projetos, a necessidade de recursos com estimativa de custos e a elaboração e apresentação do plano e do relatório final.

\section{REFLEXÕES SOBRE A APLICAÇÃO DO SIE NO PROCESSO DE GESTÃO}

Para realizar o desenvolvimento de um sistema de informações executivas, deve-se optar por uma metodologia que possibilite atingir os objetivos propostos pela organização. Para tal escolheu-se combinar princípios da Engenharia da Informação e o Método de Análise dos Fatores Críticos de Sucesso.

Pozzebon e Freitas (1996, p.22) afirmam que se os projetistas de um SIE se basearem nas modelagens dos sistemas de informação, somente nas metodologias mais utilizadas, tais como análise estruturada de sistemas ou engenharia de informação, dificilmente o proje- 
to terá êxito. Afirmam, ainda, que, no momento de informatizar uma organização, os sistemas de informação automatizam funções, procedimentos e tarefas delimitadas. Já a tomada de decisão não é caracterizada por atividades repetitivas e bem definidas, e os cenários envolvidos na tomada de decisão estão em constante mudança. Dessa forma, entendem que a contribuição da Engenharia de Informação "está contida, sobretudo, no Planejamento de Informática, uma das etapas que compõem a fase de planejamento."
Por outro lado, o Método de Análise dos Fatores Críticos de Sucesso lida com os mesmos conceitos de missão, objetivos da empresa, objetivos da área funcional, fatores críticos de sucesso, necessidades de informação, problemas e indicadores de desempenho. Estes componentes formam, segundo Furlan, Ivo e Amaral (1994, p.69), o esquema conceitual do inter-relacionamento dos objetos do SIE e que devem nortear seu desenvolvimento. A Figura 3 apresenta este esquema.

Figura 3 - Esquema conceitual do inter-relacionamento dos objetos do SIE

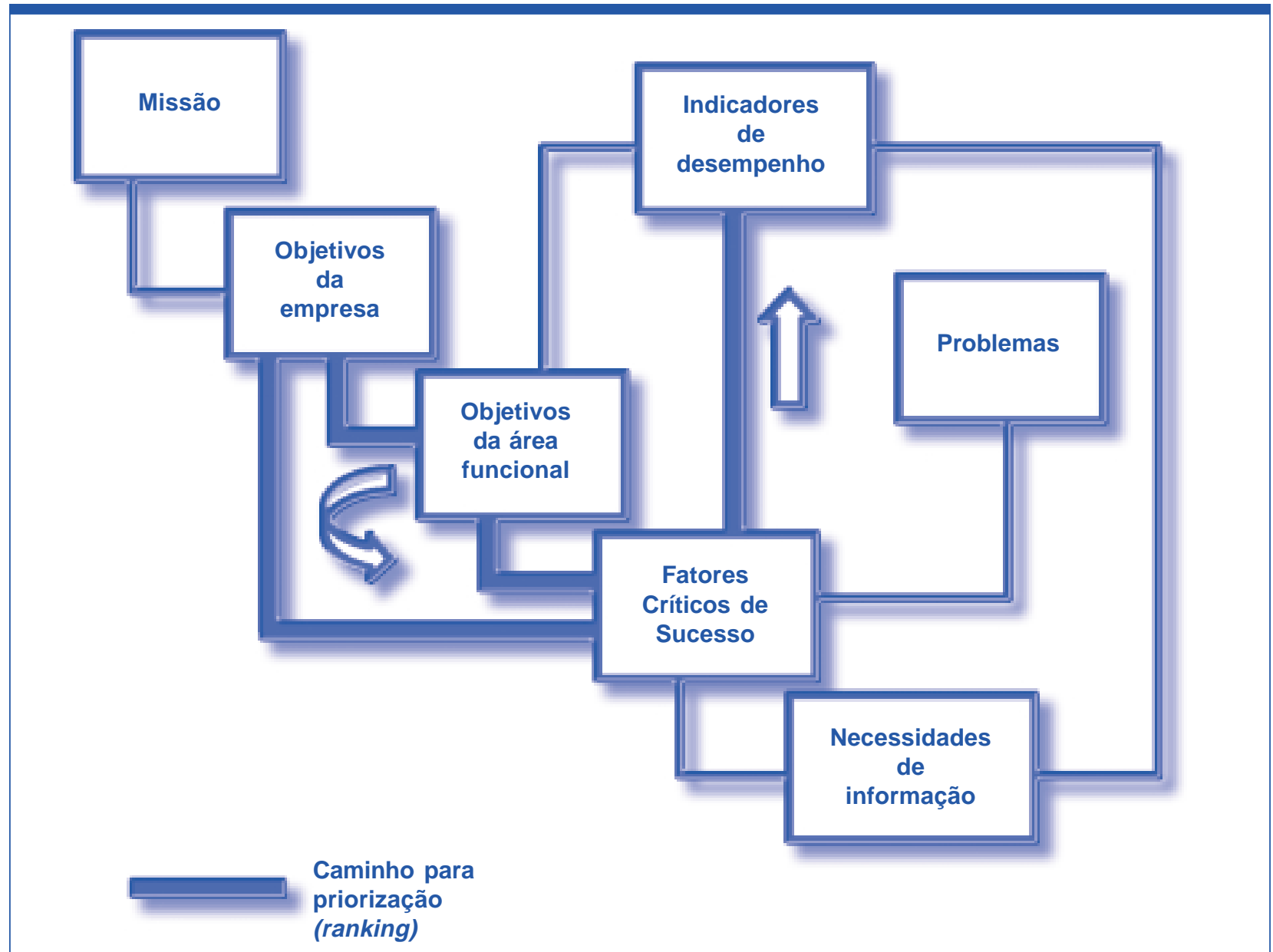

Fonte: FURLAN, José Davi, IVO, Ivonildo da Motta e AMARAL, Francisco Piedade. Sistema de Informação Executiva=EIS-Executive Information System: como integrar os executivos ao sistema informacional das empresas, fornecendo informações úteis e objetivas para suas necessidades estratégicas e operacionais. São Paulo: Makron Books, 1994. p. 69.

O esquema demonstra as ligações entre os objetos do SIE e estabelece o caminho metodológico para a compreensão das necessidades do negócio. Estabelece a missão da organização para, em seguida, relacionar os respectivos objetivos da instituição. Para encontrar as necessidades de informação, relacionam-se os objetivos da área funcional com os objeti- vos da empresa e os fatores críticos de sucesso com os objetivos empresarias e funcionais.

O caminho para priorização (ranking) determina a ordem segundo a qual as necessidades de informação serão implantadas como parte do SIE. Como suporte ao processo de análise de impacto e atribuição de pesos, pode-se elaborar esta escala de prioridades. 
Os Fatores Críticos de Sucesso, de acordo com Rockart (1979, p.85), para qualquer negócio, são "um número limitado de pontos, cujos resultados, se forem satisfatórios, asseguram uma performance competitiva bem sucedida para a organização. São aquelas poucas áreas-chave onde as coisas devem dar certo para o negócio vigorar." Afirma que os fatores críticos de sucesso devem ser baseados nos objetivos organizacionais ligados a eles. No caso da indústria automobilística, explica que os maiores fatores críticos de sucesso refletem-se no estilo do carro, numa eficiente distribuição, na economia de combustível e um forte controle do custo de manufatura.

Para Furlan (1997, p.15), os fatores críticos de sucesso apresentam "uma visão estratégica que considera não apenas o momento atual, mas, principalmente, aspectos mais permanentes e abrangentes do negócio." Por sua vez, Cruz (1998, p.137) entende que os fatores críticos de sucesso "são pontos fundamentais, que devem ser perseguidos para que a atividade tenha sucesso."

Os fatores críticos de sucesso, quando bem gerenciados, garantem o desempenho competitivo da organização. A situação atual deve ser constantemente monitorada por meio da análise dos indicadores de desempenho desses fatores críticos.

No que concerne à necessidade de informação, Bio (1985, p.120) menciona que o gestor requer tipos diferentes de informação. "Desde que o interesse da alta administração repouse primariamente no planejamento global e no acompanhamento da sua execução, a informação oferecida deve possibilitar-lhe a verificação da eficiência e dos resultados das operações da empresa no seu todo e planejar para o futuro."

Segundo Pozzebon e Freitas (1996, p.21), observa-se que os profissionais que atuam no nível estratégico do negócio são responsáveis por definição de metas e acompanhamento de resultados. São exemplos de necessidade de informação: a) níveis de qualidade do produto; b) vendas previstas e realizadas; c) alunos ingressantes e formados; e d) participação dos concorrentes no mercado. Para tanto, a metodologia de desenvolvimento do SIE deve contemplar as necessidades de informação como suporte ao atendimento dos fatores críticos de sucesso.

Em se tratando dos indicadores de desempenho, conforme Furlan, Ivo e Amaral (1994, p.67), estes servem como um direcionador no cumprimento dos obje- tivos traçados pela organização. Eles referem-se, normalmente, aos seguintes pontos: a) metas estabelecidas versus resultados alcançados; b) comparação dos resultados da organização versus resultados dos concorrentes; e c) comparação com períodos anteriores. São exemplos de indicadores de desempenho o volume de vendas, taxa de crescimento, participação de mercado e taxa de ociosidade.

A partir da apresentação do esquema conceitual de inter-relacionamento dos objetivos da organização com o SIE, apresentam-se, a seguir, duas metodologias de análise para o desenvolvimento de um SIE que possibilite atingir os objetivos propostos pela organização: a metodologia da Engenharia da Informação e o Método de Análise dos Fatores Críticos de Sucesso, recomendado por John F. Rockart.

\section{Metodologia da Engenharia da Informação}

De acordo com Martin apud Lima (1998, p.01), a engenharia da informação pode ser definida como "a aplicação de um conjunto interligado de técnicas formais de planejamento, análise, projeto e construção de sistemas de informações sobre uma organização como um todo ou em um dos seus principais setores."

A engenharia da informação é conceituada por Feliciano Neto, Furlan e Higa (1988, p.02) como sendo "um conjunto de técnicas e lógicas formais, aplicadas na tétrade de dados, atividades, tecnologia e pessoas, que permite planejar, analisar, projetar, construir e manter sistemas de processamento de dados, de forma integrada e interagente."

No que concerne às fases da engenharia da informação, Martin apud Lima (1998, p.15) relaciona as seguintes: a) planejamento estratégico de informações; b) análise da área de negócios; c) projeto do sistema; e d) construção.

A fase de planejamento estratégico de informações consiste em identificar a missão da organização, os objetivos da empresa, os objetivos específicos de cada área funcional, os fatores críticos de sucesso necessários para atingir os objetivos, os fatores críticos de sucesso não satisfeitos que impedem atingir os objetivos e as informações necessárias para apoio a cada fator crítico de sucesso.

A segunda fase da engenharia da informação, análise das áreas de negócio, tem como finalidade a 
elaboração do modelo de dados e o dicionário de dados de cada área de negócio, considerando cada fator crítico de sucesso e as necessidades de informações.

O projeto do sistema consiste na terceira fase do método. Nesta é definido o banco de dados, o projeto estruturado do sistema, o projeto de testes do sistema, o projeto do treinamento dos usuários e a especificação dos programas.

Como quarta e última fase, a construção do sistema implementa a codificação dos programas, realizam-se os testes individuais e integrados de cada módulo, e os procedimentos de operação. É neste momento, também, que se inicia o treinamento, instala-se o sistema no ambiente de produção e obtémse a aprovação do usuário.

Por fim, cabe ressaltar que este método constituise numa maneira tradicional de desenvolvimento de sistemas. Cruz (1998, p.133) afirma que os sistemas de informação eram construídos de forma segmentada, restringindo-se a apenas uma área funcional da organização. Considera que não havia preocupação em integrar processos através de um sistema de informação, em virtude de não existir essa preocupação no mundo físico.

De modo mais específico, Pozzebon e Freitas (1996, p.22) advertem que a engenharia de informação não é a metodologia mais adequada para o desenvolvimento do SIE. Entretanto, afirmam que a apli- cação deste método implica o pensar e repensar a existência da organização, "gerando um processo que identifica e organiza as características básicas da empresa para que seus recursos e capacidades possam ser utilizados de maneira efetiva em uma direção definida."

\section{Método de Análise dos Fatores Críticos de Sucesso}

Segundo Furlan, Ivo e Amaral (1994, p.92), "a análise dos fatores críticos de sucesso baseia-se na pesquisa pioneira de Rockart, do MIT (no Massachusetts Institute of Tecnology)." Entende que "o ponto central de uma metodologia EIS deve ser o processo de análise dos fatores críticos de sucesso, para determinar os indicadores de desempenho que propiciam o alcance dos objetivos propostos e para garantir o sucesso na realização da missão empresarial."

A utilização deste método, conforme Cruz (1998, p.148), permite que sejam focados os pontos principais de uma atividade e restringe a necessidade da adoção de tecnologia da informação ao que é fundamental.

A metodologia de John F. Rockart, de acordo com Pozzebon e Freitas (1996, p.23), foi decomposta em fases e subfases. Estas divisões podem ser visualizadas no Quadro 5.

\section{Quadro 5 - Fases do Método de Análise dos Fatores Críticos de Sucesso}

\begin{tabular}{|c|l|}
\hline Fases/Subfases & \multicolumn{1}{|c|}{ Processos/Atividades } \\
\hline Primeira Fase - & Planejamento \\
\hline Subfase 1 - & Organização do projeto \\
\hline Subfase 2 - & Definição de informaçães básicas e indicadores \\
\hline Subfase 3 - & Análise e consolidação das informações \\
\hline Subfase 4 - & Desenvolvimento do protótipo \\
\hline Segunda Fase - & Projeto \\
\hline Subfase 1 - & Modelagem da aplicação \\
\hline Subfase 2 - & Definição da arquitetura tecnológica \\
\hline Terceira Fase - & Implementação \\
\hline Subfase 1 - & Construção da aplicação \\
\hline Subfase 2 - & Instalação de hardware e de software \\
\hline Subfase 3 - & Treinamento e implementação \\
\hline
\end{tabular}

Fonte: Adaptado de POZZEBON, Marlei e FREITAS, Henrique M. R. Construindo um E.I.S. (enterprise information system) da (e para) empresa. Revista de Administração, São Paulo, v.31, n.4, p.19-30, out/dez 1996. p.23. 
A fase de planejamento tem como objetivo compreender a área de negócio da organização. Busca, dessa forma, identificar as necessidades de informação dos gestores e os seus estilos decisórios. Ao fim desta etapa é possível visualizar um protótipo do sistema SIE.

$\mathrm{Na}$ subfase que contempla a organização do projeto são definidas a equipe de trabalho e as possibilidades do que o SIE pode proporcionar à organização. Dessa forma, cursos e sessões com os executivos são recomendados. É feito um levantamento das informações recebidas por diretores e o presidente da organização. Ressalta-se que nesta etapa deve ser definido o software utilizado para o desenvolvimento do SIE.

A segunda subfase corresponde à definição de informações básicas e indicadores. Para isso, são realizadas entrevistas individualizadas com os executivos para se determinarem os objetivos, fatores críticos de sucesso, necessidade de informação e requisitos do sistema.

A subfase de análise e consolidação das informações tem por finalidade gerar uma lista contendo os objetivos, fatores críticos de sucesso, problemas, necessidades de informação e indicadores de desempenho. Procede-se, também, à priorização dos objetivos e fatores críticos de sucesso a serem desenvolvidos no SIE através do ranking que estabelece esta classificação.

Com as subfases de levantamento e consolidações das informações concluídas, pode-se criar o protótipo do sistema. A quarta subfase, portanto, implementa os desenhos das telas, projeta a estrutura de navegação do sistema e elabora os layouts-padrão das telas, como cores, botões e ícones. A prototipação é construída para demonstrar ao executivo uma visão mais próxima da realidade do sistema após a sua implementação.

A finalidade principal da segunda fase, o projeto, é a definição da solução técnica para implementar o projeto conceitualmente concebido. Entre outras atividades, é definida a arquitetura tecnológica, são planejados os critérios de integração e transferência de dados entre os sistemas envolvidos, é modelada a base de dados do SIE, são definidos os atributos das tabelas e os layouts de arquivos.
A subfase modelagem de dados identifica as fontes de informação, quais as bases de dados a serem acessadas nos sistemas que têm dependência. A definição das telas e a escolha dos gráficos mais adequados para cada tipo de informação são fundamentais. Outra tarefa não menos importante compreende o estudo dos níveis de detalhamento desejados (drill down) para cada indicador de desempenho.

A subfase de definição de arquitetura tecnológica determina a localização física das bases de dados e os recursos necessários para investimentos das instalações do parque tecnológico exigido. Normalmente, quatro camadas são analisadas para suportar o SIE:

a) Interface com o usuário - envolve menus, botões, caixas de diálogo, entre outros recursos, pois é através destes que o usuário visualiza e manipula os dados.

b) Acesso aos dados - responsável pela captura de informações de várias fontes, como bancos de dados externos, aplicações locais e Internet.

c) Fonte de dados - onde os dados estão gravados - no caso do SIE, os dados podem estar armazenados em qualquer lugar.

d) Comunicação - responsável pela comunicação entre usuários do SIE. A tecnologia mais utilizada é o correio eletrônico, tanto pela Internet quanto numa rede interna, onde se permite o acesso a documentos, mensagens e dados entre os usuários do sistema.

Como terceira e última fase, a implementação destina-se a construir o sistema projetado e prototipado, instalar os recursos requisitados na definição da arquitetura tecnológica e instalar o sistema fisicamente, para que possa ser adotado pelos executivos.

A subfase de construção da aplicação é um estágio de caráter notadamente técnico. De acordo com o padrão estabelecido no projeto, com o modelo de navegação considerado mais adequado e a prototipação construída para atender um módulo, são desenvolvidas todas as telas de cada módulo restante. Uma outra tarefa a ser considerada é a realização de testes. É necessário aplicar um volume maior de dados a serem contemplados pelo SIE, para verificar, entre outros elementos, o tem- 
po de resposta, congruência na análise dos dados e a integridade da base de dados.

A subfase de instalação de hardware e software consiste em implementar a parte física do sistema, providenciando a instalação da arquitetura tecnológica projetada na fase anterior. Dessa forma, são instalados, configurados e testados para os usuários, o computador, a rede e o sistema operacional. Em seguida, instala-se o SIE desenvolvido.

A subfase de treinamento e implementação torna disponível o sistema para o executivo, de modo a incorporá-lo ao seu cotidiano. Realiza-se de treinamento e orientação para a efetiva utilização do SIE.

A aplicação do Método de Análise dos Fatores Críticos de Sucesso permite que seu ciclo de desenvolvimento se encerre em dois ou três meses. Não obstante, a concepção de um SIE, utilizando esta técnica, segundo Pozzebon e Freitas (1996, p.19), é apropriada devido à característica que esta metodologia tem em abordar "o caráter nãoprocedural dos momentos de tomada de decisão e as necessidades de informações dos decisores."

Outro aspecto não menos importante, está na criação de um protótipo do sistema, ainda na fase de planejamento. Esta implementação possibilita a concretização das idéias e visões de ambas as partes envolvidas no projeto, os executivos e os técnicos de informática. Dessa forma, reduzem-se as chances de insucesso do projeto em virtude de não satisfazer às necessidades dos usuários. Outras vantagens da prototipação são a redução de custo na manutenção do sistema após sua implantação, evita o desgaste de retornar a fases anteriores do projeto por falha na comunicação e limita o escopo do sistema com consentimento do executivo.

\section{CONCLUSÃO}

Os sistemas de informação devem atender às necessidades de cada área da organização e estar em conformidade com os preceitos estabelecidos na missão da instituição. Assim, os sistemas de informação amparam os administradores de todos os níveis para desenvolverem suas tarefas e atingir seus objetivos.

Os sistemas de informação são classificados em dois grandes blocos: os sistemas de apoio às operações e os sistemas de apoio à gestão. $O$ primeiro grupo abrange o sistema de automação (SA) e o sistema de processamento de transações (SPT). O SA tem como objetivo automatizar processos onde haja a mínima intervenção do ser humano, enquanto que o SPT tem a incumbência de processar e registrar as transações que são realizadas na organização.

O segundo bloco contempla os níveis gerenciais e estratégicos da corporação. No nível gerencial concentram-se o sistema de informações gerenciais (SIG) e o sistema de apoio a decisão (SAD). O SIG possibilita ao administrador visualizar as atividades realizadas na sua área funcional, por meio de apontamentos resumidos e sumarizados. O apoio à tomada de decisões é fornecido ao gerente pelo SAD, o qual oferece subsídios relevantes que permitem a escolha de alternativas para situações específicas. Em termos estratégicos, o sistema de informações executivas (SIE) é uma ferramenta que proporciona ao executivo o monitoramento constante dos fatores críticos de sucesso do negócio, por meio dos status indicadores de desempenho. Auxilia na exploração de dados, permitindo, assim, a identificação de problemas e oportunidades para o cumprimento da missão da organização.

Os sistemas de informação têm uma relação direta com o processo de gestão, pois são eles que dão o suporte informacional a todas as áreas da organização, contemplando as etapas do processo de gestão. Em particular, o relacionamento existente entre o sistema de informações executivas e o processo de gestão compreende:

- a natureza do SIE em oferecer suporte ao nível estratégico da instituição;

- seu caráter de ferramenta de acompanhamento dos fatores críticos de sucesso;

- a formatação e disponibilização da informação estratégica;

- o fato de que o SIE propicia o aumento da qualidade da tomada de decisão; e

- a preocupação do SIE em determinar as informações necessárias ao cotidiano do gestor.

Estes elementos fazem do SIE uma ferramenta estratégica no amparo ao processo de gestão, proporcionando ao gestor um ambiente favorável para 
o desempenho do planejamento e a otimização e monitoramento das tarefas executadas. As características esperadas de um sistema de informação voltado aos gestores responsáveis pelas tomadas de decisões estratégicas são:

- drill down (a partir de dados sumarizados, disponibilizar os detalhes dos mesmos);

- acesso a informações externas ao ambiente da empresa;

- utilização de recursos gráficos na apresentação dos resultados;

- o fato de permitir a recuperação rápida da informação;

- o fato de facilitar o uso operacional do sistema;

- o fato de estar voltado ao acompanhamento dos fatores críticos de sucesso através dos indicadores de desempenho; e

- de realizar a triagem de informações, filtrando e resumindo-as.

Assim a configuração de um SIE específico à gestão da empresa, baseado nos anseios dos seus gestores, permeia os aspectos da formação da base de dados do sistema: condições facilitadas de acesso aos estatutos, normas, atas, editais, regulamentos, projetos etc, condições de realizar projeções, simulações e análise para apoio às decisões; acompanhamento dos fatores críticos de sucesso; acesso a outros sistemas de informação, assim como aos sistemas de automação de escritório e de comunicação; e procedimentos de segurança do próprio SIE.

As fontes de informação externas e internas, bem como os dados históricos e estruturais da organização, possibilitariam a criação do banco de dados, base informacional em todos os pontos do sistema.

Pelo recurso de hipertexto, seriam proporcionadas condições para acesso ao sistema, dos estatutos, normas, atas, editais, regulamentos e projetos, entre outros documentos da empresa.

As projeções, simulações e análise traçariam panoramas para detecção de problemas e oportunidades, assim como realizariam comparações e avaliariam desempenho. Isto refletiria no planejamento de novas atividades e controle das existentes.

O acompanhamento dos fatores críticos de sucesso possibilitaria verificar a condução aos objetivos da organização e ao cumprimento da sua missão.

A operacionalização para acesso a outros sistemas de informação e software de automação de escritório e comunicação permitiria o uso facilitado do sistema e a criação de um ambiente único de trabalho.

Os procedimentos de segurança garantiriam sigilo e restrição do acesso às informações estratégicas da instituição, somente para aqueles que fossem autorizados a usar o SIE.

Portanto, a partir do que foi exposto, o presente artigo permitiu um refinamento das categorias dos sistemas de informação, e, em particular, ofereceu um referencial como base para o desenvolvimento e utilização de um sistema de informações executivas no ambiente de uma organização.

REFERÊNCIAS BIBLIOGRÁFICAS

ACKOFF, Russel L. Planejamento empresarial. Rio de Janeiro: LTC, 1981.

ALMEIDA, Lauro Brito de. Sistema de informações de gestão econômica. In: CATELLI, Armando (coordenador). Controladoria: uma abordagem da gestão econômica - GECON. São Paulo: Atlas, p. 300314, 1999.

ALTER, Steven. Information system: a management perspective. United States of America: Addison-
Wesley Publishing Company, 1992.

BEUREN, Ilse Maria. Gerenciamento da informação: um recurso estratégico no processo de gestão empresarial. São Paulo: Atlas, 1998.

CAMPOS FILHO, Maurício Prates. Os sistemas de informação e as modernas tendências da tecnologia e dos negócios. Revista de Administração de Empresas, São Paulo, v.34, n.6, nov/ dez 1994, p.33-45. 
CRUZ, Tadeu. Sistemas de informações gerenciais: tecnologia da informação e a empresa do século XXI. São Paulo: Atlas, 1998.

DALFOVO, Oscar e RODRIGUES, Leonel Cezar. Delineamento de um sistema de informação estratégico para tomada de decisão nas pequenas e médias empresas do setor têxtil de Blumenau. Revista de Negócios, Blumenau, v.3, n.3, 1998, p.43-56.

DAMIANI, Wagner Bronze. Estudo do uso de sistemas de apoio ao executivo. In: ENANPAD, 22, 1998, Foz do Iguaçu. Resumos...Rio de Janeiro: ANPAD, 1998. p. 40. CD-ROM.

FELICIANO NETO, Acácio, FURLAN, José Davi e HIGA, Wilson. Engenharia da informação: metodologia, técnicas e ferramentas. 2 ed. São Paulo: McGraw-Hill, 1988.

FISCHMANN, Adalberto A. e ZILBER, Moisés Ari. Utilização de indicadores de desempenho como instrumento de suporte à gestão estratégica. In: ENANPAD, 23, 1998, Foz do Iguaçu. Resumos... Rio de Janeiro: ANPAD, 1999, CD-ROM, p.173.

FURLAN, José Davi, IVO, Ivonildo da Motta e AMARAL, Francisco Piedade. Sistema de Informação Executiva=EIS-Executive Information System: como integrar os executivos ao sistema informacional das empresas, fornecendo informações úteis e objetivas para suas necessidades estratégicas e operacionais. São Paulo: Makron Books, 1994b.

FURLAN, José Davi. Como elaborar e implementar o planejamento estratégico de sistemas de informação. São Paulo: Makron, McGraw-Hill, 1991.

. Modelagem de negócio. São Paulo: Makron Books, 1997.

LIMA, Eliana Sangreman et al. Concepção e aplicação de sistema de informação para expectativa de resultado de desempenho estratégico. In: ENANPAD, 22, 1998, Foz do Iguaçu. Resumos...Rio de Janeiro: ANPAD, 1998, , CDROM, p.39.

MCLEOD JR., Raymond. Management information system: a study of computer-base information system. United States of America: Macmillan Publishing Company, 1993.

MOSIMANN, Clara Pellegrinello, ALVES, Osmar de C. e FISCH, Silvio. Controladoria: seu papel na administração de empresas. Florianópolis: Ed. da UFSC, 1993.

OLIVEIRA, Djalma de Pinho Rebouças de. Sistemas de informações gerenciais: estratégicas, táticas, operacionais. São Paulo: Atlas, 1992.

POZZEBON, Marlei e FREITAS, Henrique M. R. Construindo um E.I.S. (enterprise information system) da (e para) empresa. Revista de Administração, São Paulo, v.31, n.4, out/dez 1996, p.19-30.

POZZEBON, Marlei. Um modelo de E.I.S. - Enterprise Information System - que identifica características para comportamentos proativos na recuperação de informações. Dissertação - Universidade Federal do Rio Grande do Sul, Porto Alegre, 1998.

ROCKART, John F. Chief executives define their own data needs. Harvard Business Review, mar/abr 1979, p.81-92.

SPRAGUE JR., Ralph H. Estrutura para o desenvolvimento de sistemas de apoio à decisão. In: SPRAGUE JR., Ralph H. e WATSON, Hugh J. (Org.). Sistemas de apoio a decisão: colocando a teoria em prática. Rio de Janeiro: Campus, 1991, p.09-42.

STAIR, Ralph M. Princípios de sistemas de informação: uma abordagem gerencial. Rio de Janeiro: LTC - Livros Técnicos e Científicos, 1998.

TURBAN, Efraim e SCHAEFFER, Donna M. Uma comparação entre sistemas de informação para executivos, DSS e sistemas de informação gerencial. In: SPRAGUE JR, Ralph H. eWATSON, Hugh J. (Org.). Sistemas de apoio à decisão: colocando a teoria em prática. Rio de Janeiro: Campus, 1991, p.345-362.

TURBAN, Efraim. Decision Support and expert systems: management support systems. United States of America: Macmillan Publishing Company, 1993. 